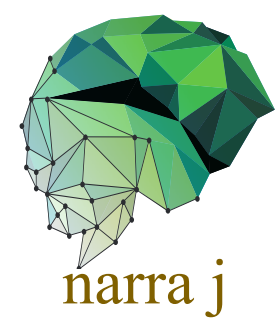

Short Communication

\title{
Accuracy of Meningitis Bacterial Score (MBS) as an indicator in establishing the diagnosis of acute bacterial meningitis in adults
}

\author{
Imas R. Palupi ${ }^{1,2}$ and Paulus Sugianto ${ }^{1,2}$ \\ ${ }^{1}$ Department of Neurology, Faculty of Medicine, Universitas Airlangga, Surabaya, Indonesia; ²Department of Neurology, \\ Dr. Soetomo Hospital, Surabaya, Indonesia \\ *paulus.sugianto.unair@gmail.com
}

\begin{abstract}
Bacterial meningitis persists as a worldwide threat contributing to high mortality and morbidity rate, where differentiating bacterial meningitis from aseptic meningitis is key for better management and outcomes. Hence, this study aimed to assess the Bacterial Meningeal Score (BMS) as a tool for early diagnosis of acute bacterial meningitis. This study employed a retrospective cross-sectional method using medical records of patients with meningitis and meningoencephalitis who were hospitalized at Dr. Soetomo Hospital, from January 2018 to September 2021. Data of demographics, clinical, laboratory and cerebrospinal fluid (CSF) profile and culture were collected. The diagnostic performance of the BMS in diagnosing acute bacterial meningitis was evaluated by its sensitivity, specificity, positive predictive value (PPV), negative predictive value (NPV), positive likelihood ratio (LR +) and negative likelihood ratio (LR -). A total of 128 patients who had been diagnosed with meningitis and meningoencephalitis were included. Out of total patients, 53 samples were diagnosed with acute bacterial meningitis as confirmed by CSF culture. The sensitivity and specificity of BMS with cutoff $>2.5$ in diagnosing acute bacterial meningitis were $92.4 \%$ and $92.0 \%$, respectively with PPV 89.1\% and NPV 94.5\%. The area under the curve (AUC) of BMS in diagnosing of acute bacterial meningitis was 95.6\% (95\%CI: 92.3\%, 99\%). A BMS score of greater than 2.5 indicates a high likelihood of acute bacterial meningitis, whereas a score less than 2.5 indicates a low likelihood.
\end{abstract}

Keywords: Acute bacterial meningitis, Bacterial Meningeal Score, diagnostic, cerebrospinal fluid, meningoencephalitis

\section{Introduction}

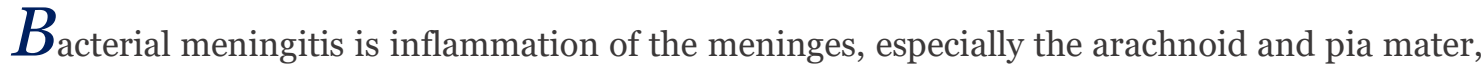
which occurs following the bacterial invasion into the subarachnoid space $[1,2]$. The inflammatory process is not limited to the meninges, but can also affect the brain parenchyma (meningoencephalitis), ventricles (ventriculitis), and possibly the spinal cord $[1,2]$. Bacterial meningitis cases can be classified as community meningitis or nosocomial infection, based on the setting of infection. Community meningitis is bacterial meningitis that is acquired spontaneously in the community. Nosocomial infections can be acquired from surgical procedures such as craniotomy, spinal surgery, lumbar drain, ventriculostomy, penetrating head trauma or skull fracture, in a hospital setting [3]. 
Bacterial meningitis is associated with a high mortality and morbidity rate, globally [4]. Approximately, there are 1.2 million cases of bacterial meningitis reported annually in the world, with over 135,000 deaths, annually [4]. The annual incidence of bacterial meningitis in Western countries such as Finland, the Netherlands, and the United States is 0.7-0.9 per 100,000 population, while in Southeast Asia the incidence rate is between 18.3-24.6 per 100,000 population [5-7]. Data from the Indonesian Ministry of Health in 2010, 19,381 cases of bacterial meningitis were reported with 1,025 deaths [4].

Secondary neurological complications of bacterial meningitis could increase the risk of disability and death. A study found that the case fatality rate (CFR) of bacterial meningitis reached $44 \%$ on day 10 and $54 \%$ on day 40 [8]. In Bali, the mortality rate of bacterial meningitis patients treated at Sanglah Hospital Denpasar was 57.4\% [9]. The most common complications of bacterial meningitis include cerebrovascular disorders, increased intracranial pressure, cranial neuropathy, seizures, and death [10]. Therefore, effective management is required from the time of diagnosis, therapy, and management of complications for the bacterial meningitis to improve the patient's outcomes $[1,11]$. Establishing a diagnosis of acute bacterial meningitis is challenging due to its difficulty in differentiating between bacterial meningitis and aseptic meningitis, until cerebrospinal fluid cultures are obtained. The wait-and-see approach could cause delays in antibiotic administration which could affect the patient's outcomes [12].

It is recommended to initiate antibiotic treatment immediately in patients with clinical evidence of acute meningitis. Antimicrobial therapy is often continued at least until bacterial culture results are available, which requires 48 to 72 hours [11]. Inappropriate administration of antibiotics will increase the incidence of antibiotic resistance, drug side effects, and the cost of hospitalization. Distinguishing between bacterial and aseptic meningitis may contribute to prevent unnecessary administration of antibiotics to the patients [13]. Therefore, a faster diagnostic modality is needed to establish the diagnosis of acute bacterial meningitis.

Bacterial Meningeal Score (BMS) is a scoring system that could be used to distinguish bacterial meningitis from aseptic meningitis. BMS is a simple scoring system and has been studied in several countries, including Indonesia. A study showed that the BMS had a sensitivity of $99.3 \%$ with a specificity of $62.1 \%$ [14]. Another study on pediatric population in Indonesia found the sensitivity and specificity of BMS could reach $83.3 \%$ and $89.5 \%$, respectively [15]. External validation of BMS had also been carried out on an adult population in the United States with a sensitivity of $100 \%$ and a specificity of $51 \%$ [16]. Herein, the accuracy of BMS was assessed in an Indonesian adult population, for the first time. Hence, the result of this study could provide more evidence regarding the accuracy of BMS in diagnosing acute bacterial meningitis, especially in the context of a developing country.

\section{Methods}

\section{Study design}

This study used a retrospective cross-sectional approach using secondary data from patients' medical records. The study population was patients with meningitis and meningoencephalitis who were hospitalized at Dr. Soetomo Hospital in Surabaya of Indonesia from January 2018 to September 2021.

\section{Selection of medical records}

All consecutive admissions of meningitis and meningoencephalitis patients were included according to the inclusion and exclusion criteria. These meningitis and meningoencephalitis cases could be bacterial meningitis or aseptic meningitis. The inclusion criteria included: (1) patients should be 18 years old or over; and (2) had been diagnosed with meningitis and meningoencephalitis based on clinical symptoms, examination on a lumbar puncture, and confirmation from cerebrospinal fluid (CSF) culture. Patients receiving intracranial antibiotic therapy for 72 hours before lumbar puncture were excluded.

The BMS was measured and calculated at the beginning of hospital admission. BMS consisted of several components: (1) positive cerebrospinal fluid gram staining (2 points); (2) 
cerebrospinal fluid protein level $\geq 80 \mathrm{mg} / \mathrm{dL}$ (1 point); (c) peripheral blood neutrophil count $\geq 10,000$ cells $/ \mathrm{mm}^{3}$ (1 point); (d) history of seizures (point 1); and (e) absolute neutrophil count in cerebrospinal fluid $\geq 1,000$ cells $/ \mathrm{mm}^{3}$ ( 1 point). BMS of $<2$ indicated that the patient was less likely to have active bacterial meningitis, meanwhile a BMS of $\geq 2$ indicated that the patient had a high likelihood of having active bacterial meningitis.

\section{Data analysis}

Predictive diagnostic values of BMS in diagnosing bacterial meningitis were presented with a sensitivity and specificity, Positive predictive value (PPV), negative predictive value (NPV), positive likelihood ratio $(\mathrm{LR}+$ ) and negative likelihood ratio (LR -). All data analysis were conducted using SPSS version 24. All data analysis were conducted using SPSS version 24.

\section{Results}

A total of 128 adult patients diagnosed with undefined meningitis or meningoencephalitis based on clinical manifestations, physical examinations and laboratory test were included in this study. Characteristics of the patients are presented in Table 1. More than a half of the patient were male (53.1\%). The mean age of the patients was $37.9 \pm 15.1$ years old (ranging from 18 to 76 years old). There were 52 (40.6\%) patients that experienced seizure, while 76 others (59.4\%) did not. As many as 4 (3.1\%) and 23 (17.9\%) patients had human immunodeficiency virus (HIV) infection and pulmonary tuberculosis (TB), respectively. Other clinical characteristics such as the levels of leukocytes, peripheral blood neutrophils, and CSF glucose are presented in Table 1.

Table 1. Characteristics of research patients with meningitis $(n=128)$

\begin{tabular}{|c|c|c|}
\hline \multirow[t]{2}{*}{ Variable } & $\begin{array}{l}\text { Meningitis or } \\
\text { meningoencephalitis } \\
\text { patients } \\
(\mathrm{n}=128)\end{array}$ & $\begin{array}{l}\text { Acute bacterial } \\
\text { meningitis } \\
(\mathrm{n}=53)\end{array}$ \\
\hline & $\mathrm{n}(\%)$ & $\mathrm{n}(\%)$ \\
\hline \multicolumn{3}{|l|}{ Gender } \\
\hline Male & $68(53.1)$ & $36(67.9 \%)$ \\
\hline Female & $60(46.9)$ & $17(32.1 \%)$ \\
\hline Age, mean $\pm \mathrm{SD}$ & $37.9 \pm 15.1$ & $41.02 \pm 15.8$ \\
\hline \multicolumn{3}{|l|}{ Age group } \\
\hline$\geq 60$ years old & $13(10.1)$ & $8(15.1)$ \\
\hline$<60$ years old & $115(89.8)$ & $45(84.9)$ \\
\hline \multicolumn{3}{|l|}{ Seizure } \\
\hline Yes & $52(40.6)$ & $21(39.6)$ \\
\hline No & $76(59.4)$ & $32(42.1)$ \\
\hline \multicolumn{3}{|l|}{ Human immunodeficiency virus (HIV) infection } \\
\hline HIV positive & $4(3.1)$ & $4(7 \cdot 5)$ \\
\hline HIV negative & $124(96.9)$ & $49(92.4)$ \\
\hline \multicolumn{3}{|l|}{ Tuberculosis (TB) history } \\
\hline Had TB infection & $23(17.9)$ & $5(9.4)$ \\
\hline No history of TB & $105(82.1)$ & $48(90.6)$ \\
\hline \multicolumn{3}{|l|}{ Laboratory parameters } \\
\hline Peripheral blood leukocyte count $\left(10^{3} / \mu \mathrm{l}\right)$, mean $\pm \mathrm{SD}$ & $12,867 \pm 5,986.9$ & $13,025 \pm 5,511.6$ \\
\hline Peripheral blood neutrophil count $\left(10^{3} / \mu \mathrm{l}\right)$, mean \pm SD & $9,560 \pm 5,580.7$ & $10,701 \pm 5,090.7$ \\
\hline Peripheral glucose (mg/dl), mean $\pm \mathrm{SD}$ & $143.6 \pm 77.2$ & $154.5 \pm 94.6$ \\
\hline \multicolumn{3}{|l|}{ Cerebrospinal fluid profiles } \\
\hline Number of cells, mean \pm SD & $154 \pm 411.1$ & $224.0 \pm 590.6$ \\
\hline Leukocytes $\left(10^{3} / \mathrm{ml}\right)$, mean $\pm \mathrm{SD}$ & $149.5 \pm 411.1$ & $217.0 \pm 579.7$ \\
\hline Erythrocytes $\left(10^{6} / \mathrm{ml}\right)$, mean $\pm \mathrm{SD}$ & $0.5 \pm 1.7$ & $1.0 \pm 2.4$ \\
\hline Percentage of PMN, mean \pm SD & $34.7 \pm 83.1$ & $48.3 \pm 124.9$ \\
\hline Percentage of $\mathrm{MN}$, mean $\pm \mathrm{SD}$ & $78.2 \pm 73.4$ & $85.2 \pm 109.6$ \\
\hline Number of PMN, mean \pm SD & $52.2 \pm 279.7$ & $96.5 \pm 429.7$ \\
\hline Number of MN cells, mean \pm SD & $97.6 \pm 202.1$ & $121.3 \pm 225.3$ \\
\hline Total protein $(\mathrm{mg} / \mathrm{dl})$, mean $\pm \mathrm{SD}$ & $377.1 \pm 884.0$ & $379 \cdot 3 \pm 757.2$ \\
\hline Glucose $(\mathrm{mg} / \mathrm{dl})$, mean \pm SD & $64.4 \pm 41.2$ & $67.7 \pm 49.7$ \\
\hline \multicolumn{3}{|l|}{ Outcomes } \\
\hline Death & $39(30.4)$ & $12(22.6)$ \\
\hline Survive & $89(69.6)$ & $41(77.4)$ \\
\hline
\end{tabular}

SD: Standard deviation; PMN: polymorphonuclear leukocytes; MN: mononuclear leukocytes 
Out of 128 patients with meningitis and meningoencephalitis, 53 patients (41.4\%) had positive CSF culture, indicating acute bacterial meningitis (67.9\% male and $32.1 \%$ female) (Table 1). The mean age of patients with acute bacterial meningitis was $41.0 \pm 15.8$ years old (range: 18 76 years old). A total of 21 (39.6\%) patients had seizures and 41 (77.4\%) patients were survived (Table 1). The mean peripheral blood leukocyte level and peripheral blood neutrophil level of the bacterial meningitis patients were $13,025 \times 10^{3} / \mu \mathrm{l}$, and $10,701 \times 10^{3} / \mu \mathrm{l}$, respectively.

CSF samples of patients with acute bacterial meningitis were analyzed and the results are presented in Table 1. The results of the CSF cultures are presented in Table 2. Several bacterial genera were identified including Acinetobacter, Acinobacter, Aerococcus, Baccillus, Brevibacillus, Cellulosimicrobium, Corynebacterium, Eschericia, Micrococcus, Pseudomonas, Staphylococcus and Streptococcus. The most common bacterial species associated with acute bacterial meningitis in our cohort were Staphylococcus species such as S. haemolyticus, $S$. hominis and S. epidermidis (Table 2).

Table 2. Bacterial profile of cerebrospinal fluid cultures from patients with acute bacterial meningitis $(\mathrm{n}=53)$

\begin{tabular}{ll}
\hline Bacteria species & $\mathrm{n}(\%)$ \\
\hline Acinetobacter baumannii & $1(1.8)$ \\
Acetobacter sp & $1(1.8)$ \\
Aerococcus viridans & $1(1.8)$ \\
Baccillus lyceniformis & $1(1.8)$ \\
B. cereus & $1(1.8)$ \\
B. circulans & $1(1.8)$ \\
B. megaterium & $1(1.8)$ \\
B. pumilus & $2(3.7)$ \\
Bacillus sp & $1(1.8)$ \\
Brevibacillus brevis & $1(1.8)$ \\
Cellulosimicrobium celular & $1(1.8)$ \\
Corynebacterium aquaticum & $1(1.8)$ \\
C. matruchotii & $1(1.8)$ \\
Escherichia coli & $1(1.8)$ \\
Micrococcus luteus & $1(1.8)$ \\
Pseudomonas aeuroginosa & $1(1.8)$ \\
P. oryzihabitans & $1(1.8)$ \\
P. stutzeri & $1(1.8)$ \\
Rhizobium radiobacter & $1(1.8)$ \\
Staphylococcus aureus & $4(7.5)$ \\
S. haemolyticus & $10(18.8)$ \\
S. capitis & $2(3.7)$ \\
S. cohnii & $1(1.8)$ \\
S. epidermidis & $5(9.4)$ \\
S. escheori & $1(1.8)$ \\
S. hominis & $7(13.2)$ \\
S. simulans & $1(1.8)$ \\
Streptococcus gordonii & $1(1.8)$ \\
S. pneumoniae & $1(1.8)$ \\
\hline &
\end{tabular}

Table 3. Diagnostic performance of BMS to diagnose acute bacterial meningitis in adults

\begin{tabular}{ll}
\hline Diagnostic parameters & Meningitis Bacterial Score \\
\hline Sensitivity (\%) & 92.4 \\
Specificity (\%) & 92.0 \\
Positive predictive value (\%) & 89.1 \\
Negative predictive value (\%) & 94.5 \\
Positive likelihood ratio & 11.5 \\
Negative predictive value & 0.08 \\
Prevalence (\%) & 41.4 \\
Accuracy (\%) & 92.5 \\
\hline
\end{tabular}

In our present study, there were 55 (43\%) patients that had a BMS $>2.5$, exceeding the cutoff for bacterial meningitis, and $73(57 \%)$ patients had BMS score $<2$. The optimal cutoff was obtained from the curve intersection of sensitivity and specificity. Out of 55 patients with a high risk BMS score (>2.5), 49 (92.5\%) were confirmed as bacterial meningitis through CSF 
culture. Among patients with BMS <2.5 (categorized as low-risk), 69 (92\%) had confirmed nonbacterial meningitis based on CSF culture. BMS diagnostic accuracy figures are presented in Table 3. Receiver operating curve (ROC) for the BMS was created and the area under the curve (AUC) was analyzed. The AUC of BMS to diagnose of acute bacterial meningitis was $95.6 \%$ (95\%CI: 92.3\%, 99\%).

\section{Discussion}

In our study, out of total 182 patients with meningitis or meningoencephalitis, 52 (40.6\%) patients had seizures, while 76 (59.4\%) patients did not experience seizures. In the cases of acute bacterial meningitis, those who showed seizure symptoms were recorded in many as 21 (39.6\%) patients, while 32 (42.1\%) patients had no clinical symptoms of seizures. In a previous study, patients with acute bacterial meningitis presenting with seizures were up to $14.4 \%$ of total samples [17]. Another investigation reported ad similar proportion (27\%) [18]. An investigation using multivariate analysis revealed that seizures were associated with the presence of structural lesions on the central nervous system, severe central nervous system infections, systemic inflammation, pneumococcal meningitis, and predisposing conditions (such as tachycardia), Glasgow Coma Scale Score at admission, infection with Streptococcus pneumoniae, and focal cerebral disorders [19]. Seizures have not been reported to be related to the pathogen type involved in bacterial meningitis, but may be associated with increased morbidity and mortality [20]. Morbidity, in the case of meningitis, is associated with a variety of factors such as intracranial hypertension, hypoxia, lactic acidosis, hypoglycemia, and autonomic dysfunction (including hyperthermia, dehydration, hypertension, hypotension, and shock [20].

The mean peripheral blood leukocyte level and the mean peripheral blood neutrophil level of patients with acute bacterial meningitis are consistent with previous studies [21, 22]. Our findings regarding the CSF profile in patients with acute bacterial meningitis was also consistent to previous studies, in which almost all patients had decreased levels of glucose in the CSF, increased levels of the protein, or white blood cell count greater than 100 [23].

However, our polymorphonuclear leukocytes counts were not consistent with previous reports, which were on average less than the mean number of mononuclear leukocytes [23]. Nonetheless, it is similar to a previous study that found no cerebrospinal fluid pleocytosis $(10 \%$ of cases) or polynuclear dominance [24]. Similar results were found in a study employing 296 patients with bacterial meningitis, where $10 \%$ of the patients did not experience pleocytosis, and $20 \%$ did not have polynuclear dominance [25]. Other studies also obtained that the dominant polynuclear was only identified in $40 \%$ of the samples $[21,26]$.

In this present study, 53 (41.5\%) of 128 patients had a positive result of Gram staining, of which 10 (7.8\%) patients had Gram-positive rods, and 36 patients (28.1\%) had gram-positive cocci staining. All Gram-positive results had positive cerebrospinal bacteria culture results. This result is higher than a previously published study, where the Gram-positive results were only $22 \%$ [27]. Another study showed Gram-positive staining proportion was 59.4\% and Gram-negative $36.3 \%$ [28]. This is probably due to differences in the characteristics of research patients, where in two previous studies, the patients were in the range of neonates to adults. The sensitivity and specificity of CSF Gram staining in diagnosing acute bacterial meningitis were $60-90 \%$ and specificity of $>97 \%$, respectively [27].

In our study, 53 (41.4\%) patients showed bacterial growth in the CSF. The most widely detected bacterial species were $S$. haemolyticus (18.8\%) and $S$. hominis (13.2\%). This result was in contrast with previous research that showed the most widely identified pathogen in adults were S. pneumoniae and N. meningitidis [29]. In our study, S. pneumoniae was obtained only $1.8 \%$, while no $N$. meningitidis was obtained. The bacterial profile of infection can be influenced by variation of time, geography and age of the patients [29].

BMS used in this study had the cutoff value of $>2.5$, showing a sensitivity and specificity of 92.4\% and $92 \%$, respectively. The sensitivity was calculated based on the its ability to determine acute bacterial meningitis. Specificity refers to the ability of the scoring system in categorizing patients without acute bacterial meningitis. We found that the PPV $89 \%$ and NPV $94.5 \%$ of BMS in diagnosing acute bacterial meningitis if the BMS with cutoff $>2.5$. An accuracy rate of $92.5 \%$ 
demonstrates the scoring tool's compliance with the standard diagnostic test. These results were different to a previous study that obtained the cutoff value of $\geq 2$ [15]. This difference is possibly due to differences in the number and age of research patients [15]. Therefore, BMS with a cutoff of $>2.5$ could be used as a screening and diagnostic tool for adult patients.

Our study has several limitations. Dr. Soetomo Hospital is the referral center for several hospitals for the Eastern region of Java Island, which does not cover the entire population of the country. We could not perform other molecular tests such as polymerase chain reaction (PCR) or viral culture to rule out the differential diagnosis of aseptic meningitis. Nonetheless, this study has a strength of being is the first study conducted in Indonesia in determining the accuracy of BMS for diagnosing acute bacterial meningitis in an adult population.

\section{Conclusions}

Our data suggests that BMS could be used as a screening tool as well as a diagnostic tool in acute bacterial meningitis. A BMS score of greater than 2.5 indicates a high likelihood of acute bacterial meningitis, whereas a score less than 2.5 indicates a low likelihood. Therefore, we recommend the use of BMS as a guide for early administration of antibiotics in the case of acute bacterial meningitis aiming to improve the patients' outcomes and to reduce unnecessary antibiotics administration.

\section{Declarations}

\section{Ethics approval}

The protocol used in this study was approved by the Health Research Ethics Committee of Dr. Soetomo Surabaya (0490/LOE/301.4.2/VI/2021). Informed consent was obtained from all participants prior to their participation in the study.

\section{Conflict of interest}

The authors declare that there is no conflict of interest.

\section{Acknowledgement}

We would like to thank to all the participants who took part in this study.

\section{Funding}

This study did not receive any specific grant from funding agencies in the public, commercial, or not-for-profit sectors.

\section{Underlying data}

Derived data supporting the findings of this study are available from the first author on request.

\section{How to cite}

Palupi IR, Sugianto P. Accuracy of Meningitis Bacterial Score (MBS) as an indicator in establishing the diagnosis of acute bacterial meningitis in adults. Narra $J$ 2021; 1(3): e66. http://doi.org/10.52225/narra.v1i3.66.

\section{References}

1. Meyfroidt G, Kurtz P, Sonneville R. Critical care management of infectious meningitis and encephalitis. Intensive Care Med 2020; 46(2):192-201.

2. Sunwoo JS, Shin HR, Lee HS, et al. A hospital-based study on etiology and prognosis of bacterial meningitis in adults. Sci Rep 2021; 11(1):6028. 
3. van de Beek D, Brouwer M, Hasbun R, et al. Community-acquired bacterial meningitis. Nat Rev Dis Primers 2016; 2:16074

4. Kementrian Kesehatan RI. Panduan Deteksi dan Respon Penyakit Meningitis Meningokokus. Available from: https://infeksiemerging.kemkes.go.id/download/E-book_PANDUAN_DETEKSI_RESPON_MM-signed.pdf (Accessed 25 October 2021).

5. Maimaiti N, Md Isa Z, Rahimi A, et al. Incidence of bacterial meningitis in South East Asia region. BMC Public Health 2012; 12(S2):A30.

6. van Ettekoven $\mathrm{CN}$, van de Beek D, Brouwer MC. Update on community-acquired bacterial meningitis: guidance and challenges. Clin Microbiol Infect 2017; 23(9):601-606.

7. Zunt JR, Kassebaum NJ, Blake N, et al. Global, regional, and national burden of meningitis, 1990-2016: a systematic analysis for the Global Burden of Disease Study 2016. The Lancet Neurology 2018; 17(12):1061-1082.

8. Wall EC, Mukaka M, Scarborough M, et al. Prediction of Outcome From Adult Bacterial Meningitis in a High-HIVSeroprevalence, Resource-Poor Setting Using the Malawi Adult Meningitis Score (MAMS). Clin Infect Dis 2017; 64(4):413-419.

9. Dedang TAD, Sudewi AAR, Gelgel AM. Karakteristik dan proporsi meningitis bakteri di Rumah Sakit Umum Pusat Sanglah Denpasar tahun 2016. Medicina 2018; 49(2):232-235.

10. Julayanont P, Ruthirago D, DeToledo JC. Bacterial meningitis and neurological complications in adults. The Southwest Respiratory and Critical Care Chronicles 2016; 4(14):5-16.

11. Young N, Thomas M. Meningitis in adults: diagnosis and management. Intern Med J 2018; 48(11):1294-1307.

12. Abdlrahman H, Alhamadi A, Al-Saddi K, et al. The Sensitivity of Bacterial Meningitis Score in Children with Acute Meningitis in Qatar. Archives of Disease in Childhood 2012; 97(Suppl 2):A240-A240.

13. Dubos F, De la Rocque F, Levy C, et al. Sensitivity of the bacterial meningitis score in 889 children with bacterial meningitis. J Pediatr 2008; 152(3):378-382.

14. Nigrovic LE, Malley R, Kuppermann N. Meta-analysis of bacterial meningitis score validation studies. Arch Dis Child 2012; 97(9):799-805.

15. Arydina A, Herini ES, Triono A. Bacterial Meningeal Score (BMS) Sebagai Indikator Diagnosis Meningitis Bakterialis di RSUP Dr. Sardjito Yogyakarta. Sari Pediatri 2016; 15(5):274.

16. McArthur R, Edlow JA, Nigrovic LE. Validation of the bacterial meningitis score in adults presenting to the ED with meningitis. Am J Emerg Med 2016; 34(7):1265-1267.

17. Tang LM, Chen ST, Hsu WC, et al. Acute bacterial meningitis in adults: a hospital-based epidemiological study. QJM 1999; 92(12):719-725.

18. Vespignani H, Al Najjar A, Kremer S, et al. Seizures, epilepsy and infectious diseases of the nervous system. Epileptic Disord 2006; 8(S1):S59-S67.

19. Zoons E, Weisfelt M, de Gans J, et al. Seizures in adults with bacterial meningitis. Neurology 2008; 70(22 Pt 2):21092115.

20. Murthy JM, Prabhakar S. Bacterial meningitis and epilepsy. Epilepsia 2008; 49 Suppl 6:8-12.

21. Huy NT, Thao NT, Tuan NA, et al. Performance of thirteen clinical rules to distinguish bacterial and presumed viral meningitis in Vietnamese children. PLoS One 2012; 7(11):e50341.

22. Lembo RM, Rubin DH, Krowchuk DP, et al. Peripheral white blood cell counts and bacterial meningitis: implications regarding diagnostic efficacy in febrile children. Pediatr Emerg Care 1991; 7(1):4-11.

23. Sigurdardottir B, Bjornsson OM, Jonsdottir KE, et al. Acute bacterial meningitis in adults. A 20-year overview. Arch Intern Med 1997; 157(4):425-430.

24. van Veen KE, Brouwer MC, van der Ende A, et al. Bacterial meningitis in diabetes patients: a population-based prospective study. Sci Rep 2016; 6:36996.

25. Bezemer D, Cori A, Ratmann O, et al. Dispersion of the HIV-1 Epidemic in Men Who Have Sex with Men in the Netherlands: A Combined Mathematical Model and Phylogenetic Analysis. PLoS Med 2015; 12(11):e1001898.

26. Viallon A, Botelho-Nevers E, Zeni F. Clinical decision rules for acute bacterial meningitis: current insights. Open Access Emerg Med 2016; 8:7-16.

27. Kasana D. Gram Negative Acute Bacterial Meningitis an Emerging Entity in a Tertiary Care Centre, New Delhi. Journal of Bacteriology \& Mycology: Open Access 2016; 3(4):267-271.

28. Zhou T, Kuang M, Huang S, et al. Epidemiological Characteristics and Drug Resistance Analysis of Cerebrospinal Fluid Microbial Infections in Wenzhou Area. Infect Drug Resist 2021; 14:2091-2103. 
Palupi et al. Narra J 2021; 1(3): e66 - http://doi.org/10.52225/narra.viiz.66

29. Brouwer MC, van de Beek D. Epidemiology of community-acquired bacterial meningitis. Curr Opin Infect Dis 2018; 31(1):78-84 